Open Access

\title{
L1 Korean vocalic transfer in adult L2 Korean learners' production of Vietnamese monophthong vowels
}

\author{
Đích Mục Đào ${ }^{1 *}$ and Anh-Thư T. Nguyễn ${ }^{2}$
}

\author{
* Correspondence: \\ dichvns@hcmussh.edu.vn \\ ${ }^{1}$ University of Social Sciences and \\ Humanities, National Vietnamese \\ University of Ho Chi Minh City, Ho \\ Chi Minh City, Vietnam \\ Full list of author information is \\ available at the end of the article
}

\begin{abstract}
This paper reports a study that investigated the role of prior native or first language (L1) phonological and phonetic learning on the integration of vowel quality features in the production of second language (L2) vowels by examining adult L2 Korean learners' production of Vietnamese monophthong vowels in an imitation and a read aloud tasks. Three groups of participants took part in the study (11 control Vietnamese, 11 Korean learners of Vietnamese, and 10 control Korean). The stimuli consisted of 9 Vietnamese monophthongs /i, e, $\varepsilon, \mathrm{a}, \mathrm{J}, \mathrm{O}, \mathrm{u}, \mathrm{\gamma}, \mathrm{u} /$ and 8 Standard Korean vowels / i, $\varepsilon$, $e, a, o, u, \wedge, \dot{f} /$. The results showed that Vietnamese vowels $/ \varepsilon /$ and /e/ produced by Korean learners merged in vowel space, proving how a phonemic merger in $\mathrm{L} 1$ can influence speakers' perception and production of non-native vowels. Moreover, the three Vietnamese vowels / $/ \mathrm{J} / \mathrm{O} /$ and $/ \mathrm{\gamma} /$ produced by Korean learners in both tasks tend to cluster together. In general, the findings of this study showed that Korean learners transfer their L1 vowel quality features into the production of Vietnamese vowels.
\end{abstract}

Keywords: Vowels, Korean, Vietnamese, Second language acquisition, Acoustic phonetics

\section{Introduction}

Second-language learners typically have a wide range of difficulties with the phonetic and phonological systems of the second language (L2). When non-native speakers learn a second language, they have often shown difficulties in perceiving and producing contrastive L2 sounds which do not exist in their native language (L1) system. Some research results showed that the failure to distinguish L2 contrasts is originated from the divergence of perception and production between L1 and L2 sound systems (Best 1995; Flege 1995). In spite of these problems, a few studies observed L2 learners' successful perception and production of new L2 contrasts regardless if the new contrasts are involved in their native sound inventory or not (Flege and Hillenbrand 1984; Bohn and Flege 1990; Jun and Cowie 1994). More prior studies have stated negative opinions about setting up a separate L2 phonetic subsystem that departs from L1 sound system. Instead of accepting the existence of separate sound systems in L2 learners, they rather argued a mutual influence between L1 and L2 phonetic systems sharing 'common' sound category (Flege 1995, 1999). Flege $(1995,1999)$ argued not only for the existence

(c) The Author(s). 2018 Open Access This article is distributed under the terms of the Creative Commons Attribution 4.0 International License (http://creativecommons.org/licenses/by/4.0/), which permits unrestricted use, distribution, and reproduction in any medium, provided you give appropriate credit to the original author(s) and the source, provide a link to the Creative Commons license, and indicate if changes were made. 
of 'common space' between L1 and L2 sound systems but also that bilinguals' native phonetic category does not remain static but it undergoes continuous modification and reorganization by reflecting new L2 sounds.

Two dominant models of cross-language vowel perception (i.e., the Perceptual Assimilation Model (PAM) (Best 1995) and the Speech Learning Model (SLM) (Flege 1995) are originated from the consideration of how the foreign vowels are assimilated to native phoneme categories. The idea of a perceptual equivalence class to account for the significant effect that some non-native vowels are more readily accommodated than others by second language learners was proposed by Flege (1987). Certain L2 sounds are sufficiently phonetically different from their nearest L1 targets to be perceived as "new" or "foreign", whereas others are sufficiently close to L1 targets to be classified as "similar", though not identical to some L1 phonemic target. Afterward, Flege and Munro (1994) proposed that phonetic distance between vowels could be related directly to distances between point targets in the Bark-scaled F1 -f 0 / F 2 -F1 plane (Syrdal and Gopal 1986).

Both the Perceptual Assimilation Model and the Speech Learning Model assumed that incorrect perceptions of L2 phones by adult L2 speakers are due to the assimilation of L2 phones to L1 categories, and this assimilation can be featured on the basis of L2 speakers' linguistic background. Best (1995) and Flege (1992, 1995) proposed that some non-native speakers' difficulty in the perception and production of L2 sounds may result from perceptual assimilation of both L1 and L2 sound systems. According to Best's (1995) Perceptual Assimilation Model, non-native speakers' perception relies on their native phonemic systems, thus, if a certain phoneme from the L2 is perceptually assimilated to their L1 system, this sound is successively perceived by non-native speakers. However, if an L2 sound is difficult to assimilate to the L1 category, non-native speakers will have trouble contrasting this sound from their native phonemic category. Best (1995) suggested two different types of assimilations. The first assimilation type is the assimilation of Single Category (SC) which deals with 'new' L2 phone's assimilation to a single L1 category. The second type is the assimilation of Two Category (TC) which shows the existence of 'similar' L2 contrasts with counterparts in L1 system.

Studies on Korean acquisition of L2 vowel system are still rare. Ingram and Park (1997) examined the perception and production of Australian English monophthongal non-back vowels:(/ i, I, e, æ, a:/) by native speakers of Korean and Japanese, at two levels of English language experience. They also examined prototypicality ratings, or perceived similarities of the foreign vowels to their nearest native (L1) phonemic targets, to evaluate models of cross-language vowel perception. Their study was the first reported case of how a phonemic merger in Korean (vowels $/ \varepsilon /$ and /e/), resulting in cross-generation differences within a speech community, can influence speakers' perception and production of non-native vowels. The effects of L1 phonological learning on vowel perception were also observed in the tendency of the Japanese, but not the Korean listeners, to normalize tokens of non-native vowels for speaker-dependent durational variation, consistent with the respective phonological roles of vowel length in Japanese and Korean. In another study, Baker and Trofimovich (2005) examined /i, I, u, $\mho$, e, $\varepsilon /$ English vowel productions by Korean-English bilinguals and the Korean and English monolinguals. The vowel production of Korean-English bilinguals was then 
compared with each of the Korean and English monolinguals' vowel production. This comparison allowed them to examine how Korean-English bilinguals' vowel production differs from each of the Korean and English monolinguals' and the result showed the difference of a degree and the direction of L1-L2 interaction between late vs early bilinguals. They found a unidirectional influence of L1 on L2 from late bilinguals' vowel production, but from early bilinguals' vowel production, a bidirectional L1 and L2 influence was observed. It seems that late bilinguals tended to rely mostly on their L1 sound category in the process of L2 production, however, early bilinguals seem to establish a new sound category for L2 contrasts distinct from their L1, which helps the early bilinguals perform more proficient L2 production. Based on their findings, Baker and Trofimovich (2005) came to a conclusion that the amount of L2 experience influences the L1 and L2 relationship and its influence between L1 and L2 is observed more prominently among early bilinguals than late bilinguals. Although the late bilinguals have a certain amount of L2 experience, their L2 experience plays very little of a role in L2 acquisition. However, early bilinguals' L2 experience helps to perceive L1 and L2 phones as distinct phonetic property. L2 learners' age plays a substantial role in the relationship between L2 experience and a successful L2 acquisition. Earlier age of L2 acquisition shows a better effect on L2 acquisition than a later age of L2 learning.

In a recent study, Jung (2016) addressed Korean adult L2 learners' developmental English vowel acquisition process by demonstrating how adult L2 learners turn their initial L2 proficiency into more advanced state, and how new L2 sound system relates with existing L1 sound system. The study hypothesized that L2 learners' phonetic category is subject to change followed by three stages of L2 vowel acquisition process: Stage 1 (Initial L2 proficiency), Stage 2 (Intermediate L2 proficiency), and Stage 3 (Advanced L2 proficiency). The study also hypothesized that L2 learners' identity /attitudes/motivation may have an influence on their L2 perception and production. The study carried out longitudinal experiments with 8 Korean adult L2 learners for 6 months. The experiments were conducted on a monthly basis and the procedure was controlled in a laboratory setting to examine any possible changes of L2 ability during L2 learning process. English tense/lax vowel contrasts $(/ \mathrm{i} /-/ \mathrm{I} /$ and $/ \mathrm{u} /-/(\mathrm{n} / \mathrm{a}) /$ ) and Korean rounded/unrounded vowels $(/(\mathrm{n} / \mathrm{a})(\mathrm{i}) /$ and $/(\mathrm{n} / \mathrm{a})(\mathrm{u}) /)$ were used for the experiments. The results demonstrated that Korean L2 learners' English vowel productions have changed to a more native-like English vowel production through their L2 learning process. Thus, in the final experiment, Korean L2 learners' English vowel production showed almost an exact similarity to native speakers' vowel production. The study also investigated the relationship between adult L2 learners' identity/motivation/attitudes and their L2 vowel perception and production. The result indicated that higher identity/attitudes/motivation may result in advanced L2 vowel perception and production. L2 learners' L2 proficiency developed gradually. Hence the L2 learners' L2 learning is able to be considered to be following the sequential development pattern accompanied by the process of L2 learning.

Studies on the acquisition of Vietnamese vowels as an L2 are even rarer. Winn et al. (2008) investigated Vietnamese monophthong vowel production by native and American adult learners. Their results suggest that American adult learners struggled to produce the opposition between the central / $\mathrm{w} /$ and back vowel /u/. The learners showed an insufficient advancement separation of these vowels as compared to native speakers. 
In this paper, we present new data and results on the role of prior L1 phonological and phonetic learning on the integration of vowel quality features in the production of L2 vowels. Specifically, this study investigates adult L2 Korean learners' production of Vietnamese monophthong vowels. The findings of this study will have an original and significant contribution to the literature because first, it presents a novel comparison: the acquisition of Vietnamese as an L2 is still understudied. Second, it contributes to the understanding of the process and nature of second language acquisition.

\section{Vietnamese and Korean vowels}

The Vietnamese vowel system contains 9 long vowels, 2 short vowels and 3 diphthongs. The long vowels are / i, $\varepsilon, \mathrm{e}, \mathrm{a}, \mathrm{\gamma}, \mathrm{o}, \mathrm{o}, \mathrm{u}, \mathrm{u} /$ /; short vowels are / $\mathrm{e} \Lambda$ /; diphthongs are /ie, ur, uo/ (Dinh and Nguyen 1998). The Vietnamese vowel system has been described differently by different researchers: as a 9-vowel system (Nguyễn 1949, 1959; Haudricourt 1952; Đoàn 1977; Kirby 2011), as a 10-vowel system (Smalley and Nguyen 1957, Le 1960, Crothers 1978), as an 11-vowel system (Thompson 1965, Han 1968), or as a 14-vowel system with three diphthongs /ie/, /ur/ and /uo/ grouped with the monophthongs (Emerich 2012). The 9-vowel system analysis lists these vowels /i e $\varepsilon$ a $\circ$ o u $\gamma \mathrm{w} / \mathrm{as}$ phonemes and the vowels $/ \mathrm{B} \Lambda /$ as allophones of phonemes /a $\gamma /$. These 9 vowels can occur in both open and closed syllables, while the vowels / $1 \mathrm{e} /$ only occur in closed syllables. In this study, we examined 9 monophthongs /i e $\varepsilon$ a $\rho$ o u $\gamma \mathrm{w} /$ in open syllables only. The 9 vowels of Vietnamese under investigation in terms of tongue raising and advancement are shown in Table 1, each phonetic symbol is followed by its equivalent letters in parentheses:

The number of monophthong phonemes of Seoul Korean varies, depending on scholars, from seven (i.e., /i, e, a, $\Lambda, o, u, \dot{\mathrm{i}} /$ ) to ten (plus $/ \varepsilon, \varnothing, y /$ ). Traditional researchers (Huh 1952, 1991; Lee 1996; Sohn 1999; Yang 1996, among others) consistently presented ten monophthongs as phonemes, probably due to the influence of the Korean writing system (Hangeul), which uses different graphemes for all those ten vowels. More recent phoneticians (Shin 2000; Hwang and Moon 2005) have argued for a reduced number of vowels (7 to 9 , instead of 10) based on acoustic phonetic research. The three front vowels $/ \varepsilon, \varnothing, y /$ are categorized differently by different researchers. In this study, we will exclude the two front rounded vowels $/ \varnothing /$ and $/ y /$ as they are regarded as diphthongs (/we/ and /wi/, respectively) by most researchers. Another disagreement is about the proper treatment of non-high unrounded vowels /e/ and the mid low (or sometimes low) vowel $/ \varepsilon /$. However, it has repeatedly been observed that these two vowels are often realized identically or merged (Shin et al. 2013; Chung et al.

Table 1 The Vietnamese vowels

\begin{tabular}{llll}
\hline Position of the tongue & front & central & back \\
Openness of the mouth & & & \\
\hline close & $i(\mathrm{i}, \mathrm{y})$ & $\mathrm{u}\left(\mathrm{u}^{\prime}\right)^{\mathrm{a}}$ & $\mathrm{u}(\mathrm{u})$ \\
Mid & $\mathrm{e}(\hat{\mathrm{e}})$ & $\gamma\left(\mathrm{o}^{\prime}\right)$ & $\mathrm{o}(\hat{\mathrm{o}})$ \\
open & $\varepsilon(\mathrm{e})$ & $\mathrm{a}(\mathrm{a})$ & $\mathrm{o}(\mathrm{o})$ \\
\hline
\end{tabular}

${ }^{a}$ The IPA symbol / $\mathrm{w}$ / is used by Dinh and Nguyen (1998); Thompson (1965); Nguyễn (1997); Đoàn (1977); Kirby (2011), and Emerich (2012) while some other authors (Han, 1966; Winn et al. 2008; and Brunelle 2015) use the symbol/ $\mathfrak{i} /$ for this vowel 
1988 and Umeda 1995). In addition, Korean is traditionally described as possessing phonologically short and long vowels. However, the length contrast seems to be disappearing in the Seoul dialect; it is preserved only in the speech of older speakers and only in the most formal speech style (citation forms) (Ingram and Park 1997). In this paper, following Yoon et al. (2015), we will investigate eight Korean vowels (namely / i, $\varepsilon, \mathrm{e}, \mathrm{a}, \mathrm{o}, \mathrm{u}, \Lambda, \mathrm{i} /)$.

\section{Study aims and plans}

The aim of this study is to investigate the role of prior L1 phonological and phonetic learning on the integration of vowel quality features in the production of L2 vowels by examining adult L2 Korean learners' production of Vietnamese monophthongs in an imitation and a read aloud tasks. The study aims to address three research questions:

1) To what extent do Vietnamese and Korean vowels, as spoken by adult Vietnamese and Korean, differ or overlap in the acoustic phonetic space?

2) Are the phonetic features of L1 Korean vowels transferred to L2 Vietnamese and how Korean learners accommodate to the target Vietnamese vowel systems?

3) How would the amount of similarity between Korean L1 and Vietnamese L2 sounds determine the degree of L1-L2 interaction in late bilinguals?

The plan of this paper is as follows. First, Vietnamese and Korean speakers were asked to produce 9 Vietnamese and 8 Korean vowels, respectively. These productions were then compared to determine the degree of cross-language similarity (or "overlap") between Vietnamese and Korean vowels. The objective was to determine the extent to which Vietnamese and Korean vowels, as spoken by adult Vietnamese and Korean, overlap in the acoustic phonetic space. Next, these Vietnamese and Korean vowels were acoustically analysed to examine the degree of cross-language similarity between them. Based on these findings, predictions of how Korean learners would organize their phonetic system(s) were made. In the second part, adult Korean learners of Vietnamese were asked to produce the same Vietnamese vowels in two tasks: an imitation and a read aloud task. These productions were then compared to those of Vietnamese and Korean speakers in part 1 to see whether the phonetic features of their L1 Korean vowels are transferred to Vietnamese, how they accommodate to the target Vietnamese vowel systems and how the amount of similarity between Korean L1 and Vietnamese L2 sounds would determine the degree of L1-L2 interaction in late bilinguals.

\section{Method}

\section{Participants}

Three groups of participants took part in the study. A 'snowball' technique and stratified random sampling methods (Wiersma 2000) were used to find suitable participants through the first researcher's colleagues, students, friends, and friends of friends (participants were asked if they could recommend other people who would be interested in the experiments). In the 'snowball' technique, participants were selected by a combination of snowball sampling (where one contact leads to introductions to further potential participants) and stratified random sampling, where the various categories of 
subjects are allocated to boxes (e.g. local resident, male) and the boxes are progressively augmented until the desired cohort of subjects has been achieved. In the present case the three boxes were: a control group of Northern Vietnamese (Hanoi), a control group of Korean speakers of Busan dialect, and native Korean L2 learners of Vietnamese from Busan University of Foreign Studies in South Korea. The Vietnamese subjects can be said to represent Northern Vietnamese (Hanoi) speakers, the control group of Korean subjects represent Korean speakers of Busan dialect, and the Korean students represent Korean L2 learners of Vietnamese.

The control group of 11 Northern Vietnamese (Hanoi) speakers ( 6 females, 5 males) were international students at Macquarie University and have lived in Australia from 6 months to 1 year. Their average age was 35.3 (standard deviation (SD) =7.2).

The control group of 10 Korean speakers ( 5 females, 5 males) were international students of the Vietnamese studies program at the University of Social Sciences and Humanities, National Vietnamese University of Ho Chi Minh City, Vietnam. They all came from Busan, South Korea and have lived in Vietnam for 6 months. Their average age was $21(\mathrm{SD}=1.4)$.

The L2 learners of Vietnamese consisted of 11 native Korean speakers ( 5 males, 6 females) recruited from second-year students of Vietnamese Department of the Busan University of Foreign Studies in South Korea. Their average age was 21 years old (SD = 1.5) and their average length of learning Vietnamese was more than 1 year (mean = 13.6 months). In the first 2 years of the four-year bachelor program in Vietnamese studies, Korean students basically learn language skills such as grammar, listening, speaking, reading and writing. In the last 2 years, they both learn the advanced language skills and the Vietnamese specialised subjects such as Vietnamese culture, Vietnamese-Korean translation and interpretation, Vietnamese via media, Vietnamese via journalism, Vietnamese history, Vietnamese literature, Vietnamese politics, etc. Since these Korean speakers had studied Vietnamese in South Korea, they had little experience interacting with native Vietnamese speakers in native- environment contexts. Because the Korean leaners started learning Vietnamese at the average age of 19.5 years, they can be considered as late learners of L2. Also, since they were only second-year students from a four-year bachelor program in Vietnamese, their level of Vietnamese can be considered as pre-intermediate level.

\section{Stimuli}

The experiment used open syllables with the initial stop consonant $/ \mathrm{t}-/$ and the nine Vietnamese vowels /i/, /e/, / / /, /u/, / / /, /a/, /u/, /o/, /o/. These vowels were then embedded in $/ t_{-} /$carrier words. Each word independently carried one of the six Northern Vietnamese tones (see Table 2). The total number of items included: (9 simple vowels $\times 6$ tones, totalling 54 items). The syllables used in the study are all "legal" syllables, most of which were familiar to the participants.

Since the Korean learners learnt Vietnamese with instructors of Northern (Hanoi) dialect, one male native speaker of Hanoi Vietnamese produced all the stimuli for the Imitation task, which were recorded at $44.1 \mathrm{kHz}$ using the built-in microphone of a laptop and the Praat software (Boersma and Weenink 2017). The stimuli were randomized in one block with the inter-stimulus interval of $6 \mathrm{~s}$. The total duration of the block is 
Table 2 Vietnamese vowel stimuli

\begin{tabular}{lllllll}
\hline $\begin{array}{l}\text { Tones } \\
\text { Words }\end{array}$ & $\begin{array}{l}\text { Level } \\
\text { tone }\end{array}$ & $\begin{array}{l}\text { Falling } \\
\text { tone }\end{array}$ & $\begin{array}{l}\text { Curve } \\
\text { tone }\end{array}$ & $\begin{array}{l}\text { Broken } \\
\text { tone }\end{array}$ & $\begin{array}{l}\text { Rising } \\
\text { tone }\end{array}$ & $\begin{array}{l}\text { Dropping } \\
\text { tone }\end{array}$ \\
\hline ti $/ \mathrm{ti} /$ & ti & tì & tỉ & tĩ & tí & tị \\
tê $/ \mathrm{te} /$ & tê & tề & tể & tễ & tế & tệ \\
te $/ \mathrm{tc} /$ & te & tè & tẻ & tẽ & té & tẹ \\
tư $/$ tur/ & tư & từ & tử & tữ & tứ & tự \\
tơ $/ \mathrm{tr} /$ & tơ & tờ & tở & tỡ & tớ & tợ \\
ta $/$ ta/ & ta & tà & tả & tã & tá & tạ \\
tu $/$ tu/ & tu & tù & tủ & tũ & tú & tụ \\
tô $/$ to/ & tô & tồ & tổ & tỗ & tố & tộ \\
to $/$ to/ & to & tò & tỏ & tõ & tó & tọ \\
\hline
\end{tabular}

$13 \mathrm{~min}$. The same stimuli were presented in written form via Powerpoint slides for the Read-Aloud task.

Each of the eight Korean vowels occurred in an / $\mathrm{h}(\mathrm{V}) \mathrm{da} /$ context. In Korean that is a typical form. For example, each verb stem combines with the particle $d a$ or $h(V) d a$ to form a root infinitive. The 8 Standard Korean vowels investigated were / i, $\varepsilon, \mathrm{e}, \mathrm{a}, \mathrm{o}, \mathrm{u}, \Lambda, \dot{\mathrm{i}} /$ ), as in hida, heda, heda, hada, hoda, huda, $h$ da and $h \mathrm{~d} a$. The chosen Korean words were disyllabic because it was impossible to find monosyllabic Korean words that had the same characteristics as the Vietnamese stimuli. Nevertheless, this difference in syllable length across the word sets in the two languages was not seen to be a limitation in comparing vowel quality in Vietnamese and Korean (see Yang 1996 and Baker and Trofimovich 2005 for an example of English and Korean vowel comparisons using monosyllabic English and disyllabic Korean word stimuli).

\section{Procedures}

\section{Read-aloud task}

The control Vietnamese participants and L2 Korean learners of Vietnamese were asked to read aloud the 54 stimuli presented on Powerpoint slides (one word for each slide) at their own pace. The order of the stimuli was randomized in a different order from the other task. Their responses were recorded by the Praat program on a laptop computer.

Similarly, the control Korean speakers read the 8 disyllabic words containing 8 Korean vowels 5 times each which were all later used in the analysis. Their responses were recorded by the Praat program on a laptop computer. It is noted that the words in Vietnamese and Korean were elicited in citation forms and the same microphone and laptop used for all recordings.

\section{Imitation task}

Only the L2 learners of Vietnamese participated in this task. The participants listened to each stimulus once through headphones and were asked to repeat after it without 
any visual aid. Their responses were recorded by the Praat program on a laptop computer. They completed imitation task before the Read-Aloud task.

\section{Assessing accuracy in the read-aloud and imitation tasks}

The recordings were judged by two phonetically trained native speakers of Vietnamese, who further identified the vowel errors made by the participants. The two native speakers evaluated the recordings and labelled the vowel of each syllable/word with a choice among the nine Vietnamese vowels or the symbol $\mathrm{x}$. That is, if a vowel is perceived as not similar to any of the Vietnamese vowels, the vowel is labelled $\mathrm{x}$. When there was any disagreement between them, the item was discarded. The two native judges agreed on most of the tokens (inter-rater agreement was $89 \%$ for the Imitation task and $80 \%$ for the Read-Aloud task), and their divergence appeared to reflect ambiguity in the productions. The learners' mean percentage accuracy and error rates for the nine Vietnamese vowels in the two tasks were calculated and summarized in confusion matrices, which are provided in Table 4. The final number of vowel judgement used in subsequent analysis were sufficient for reliable statistical analysis.

\section{Data analysis}

Acoustic analyses of the Vietnamese and Korean words were performed to determine: (1) how similar (or different) the nine Vietnamese and eight Korean vowels were across the two languages, and (2) how similar (or different) the Korean learners' nine Vietnamese vowels were from the target L2 Vietnamese and their L1 Korean.

Acoustic analyses of Vietnamese and Korean vowels were limited to the fundamental frequency $(F O)$ as well as the first two vowel formants $(F 1, F 2)$. Although it is possible that the two languages may differ significantly in other dimensions of vowel acoustics (e.g., vowel duration or diphthongization) and that Korean learners may exploit these differences to make distinctions across their two languages, analyses of these vowel properties were not possible within the present study because of the differences in syllable length across the word sets in the two languages. More specifically, the vowels were analysed by measuring fundamental frequency $(F O)$ as well as the first two vowel formants $(F 1, F 2)$ at vowel midpoint. The vowels were measured using the get pitch and formant listing commands from the Praat program (Boersma and Weenink 2017).

The vowel-formant values (in $\mathrm{Hz}$ ) were then converted to Bark scale (B) to normalize for gender and age differences in vowel production (Syrdal and Gopal 1986) by using the formula: $\mathrm{B}=26.81 /(1+(1960 / \mathrm{F}))-0.53$. Two other measures were derived from the obtained vowel-formant values: B1-B0 (B1 minus B0) and B2-B1 (B2 minus B1). B1-B0 is an estimate of vowel position in the high-low dimension, where lower values represent high vowels and higher values represent low vowels. B2-B1 is an estimate of vowel position in the front-back dimension, where lower values represent back vowels and higher values represent front vowels. The vowels were then plotted in the acoustic space with $\mathrm{B} 2-\mathrm{B} 1$ values on the $\mathrm{X}$-axis and $\mathrm{B} 1-\mathrm{B} 0$ values on the Y-axis and results were presented in Figs. 1, 2, 3, 4 and 5. 


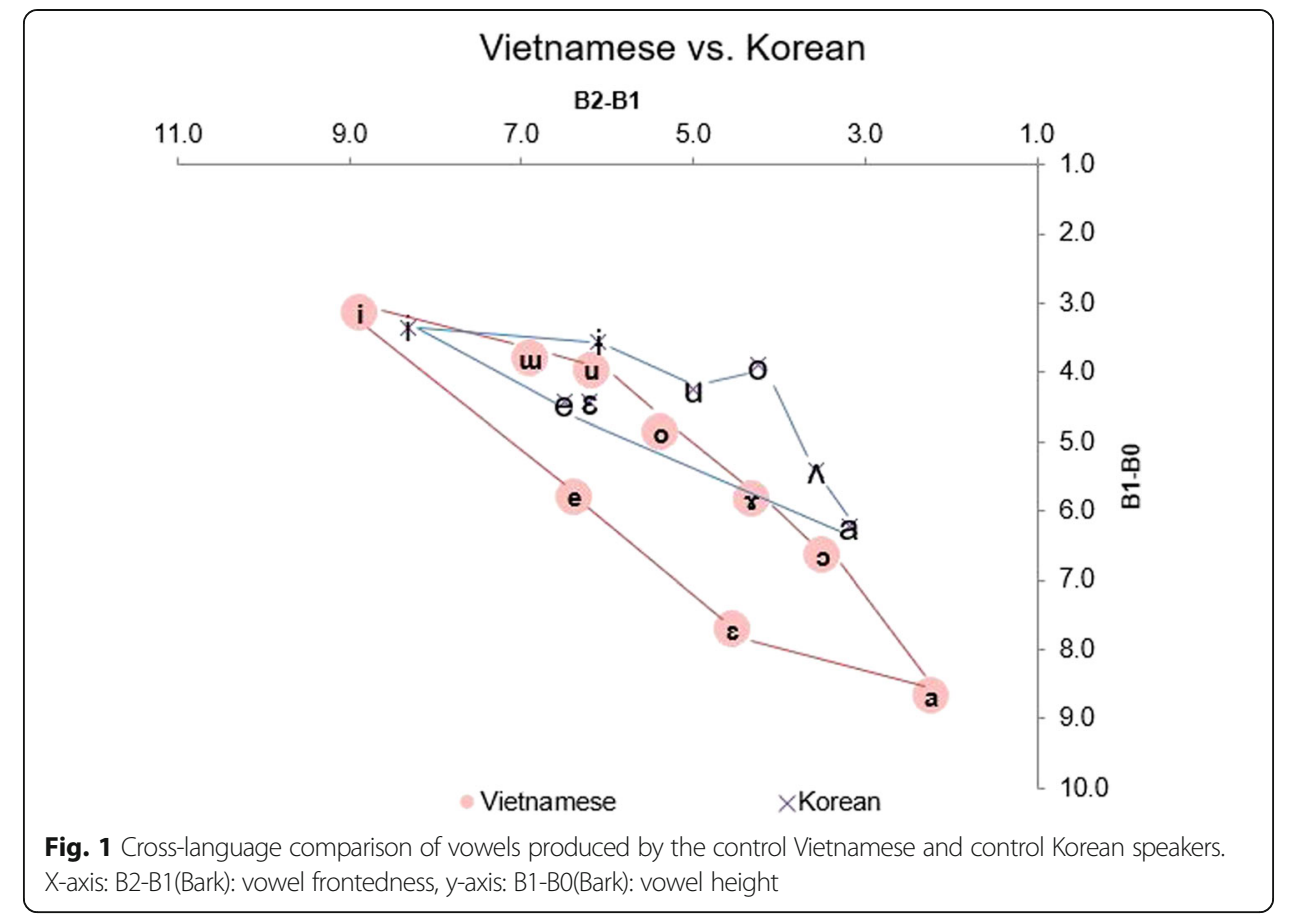

\section{Statistical analysis}

First, in order to answer the first research question, cross-language comparisons of vowels produced by the control Vietnamese and control Korean speakers were carried out within each of the vowel sets (Vietnamese /a/-Korean /a/, Vietnamese / $\varepsilon /$-Korean / $\varepsilon /$, Vietnamese /e/-Korean /e/, Vietnamese /i/-Korean /i/, Vietnamese / o/-Korean/o/, Vietnamese/o/

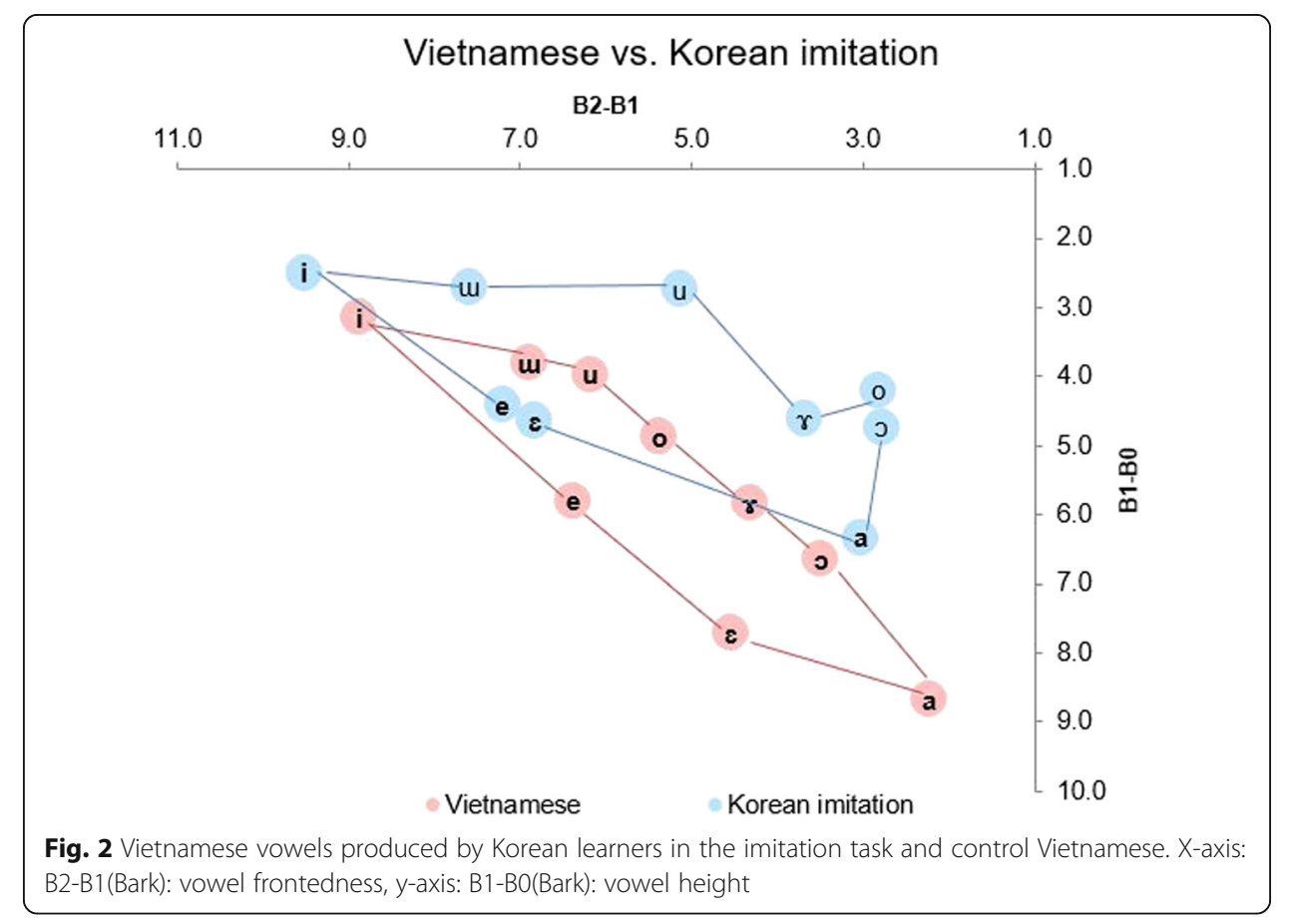




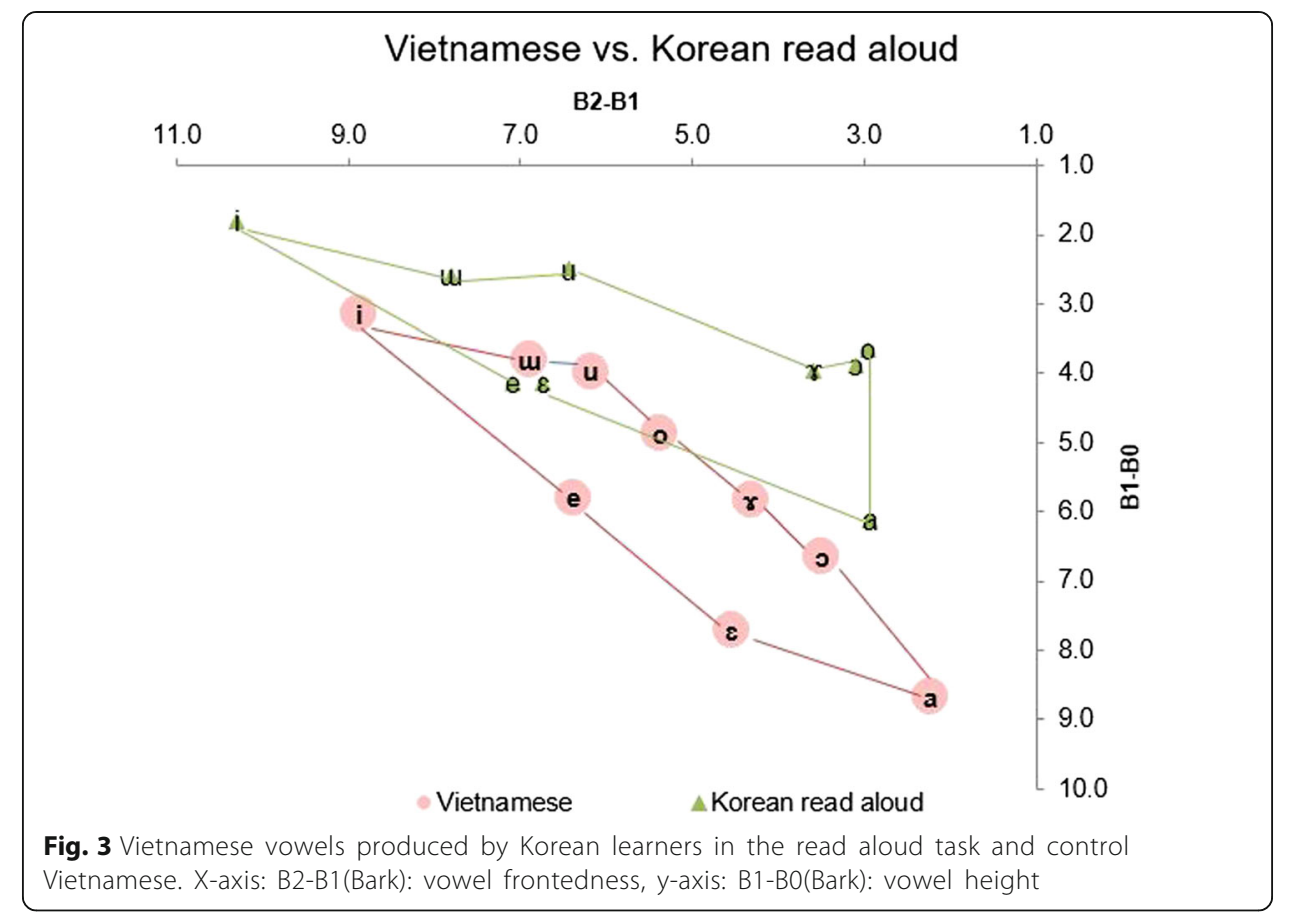

-Korean/o/, Vietnamese/ $\mathrm{\gamma} /$-Korean/ $\mathrm{\Lambda} /$, Vietnamese/u/-Korean/u/, and Vietnamese /u/ -Korean/ i/. In order to account for the effect of speakers' differences and the intrinsic segmental and tonal effects, a restricted maximum likelihood (REML) applied to mixed model methodology was performed on the vowel height (B1-B0) and vowel frontedness (B2-B1) values. The fixed effect included groups (4 groups: Korean, Korean imitation,

\section{Korean imitation}

B2-B1

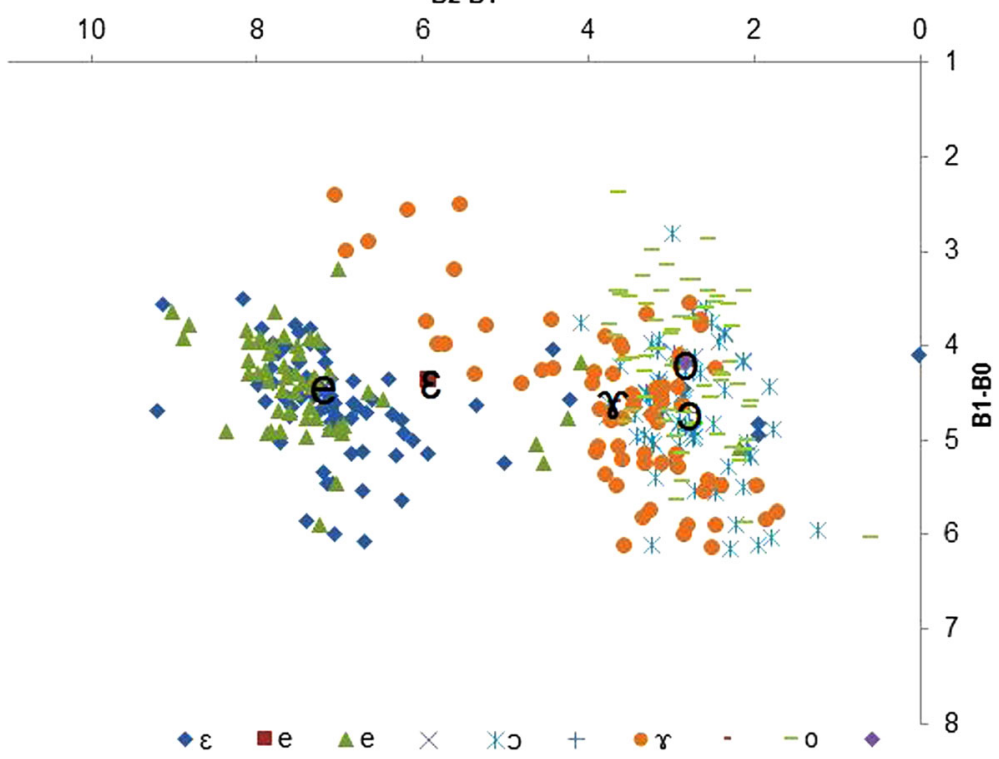

Fig. 4 The merging patterns of Vietnamese vowels produced by Korean learners in the imitation task. X-axis: B2-B1(Bark): vowel frontedness, y-axis: B1-B0(Bark): vowel height 


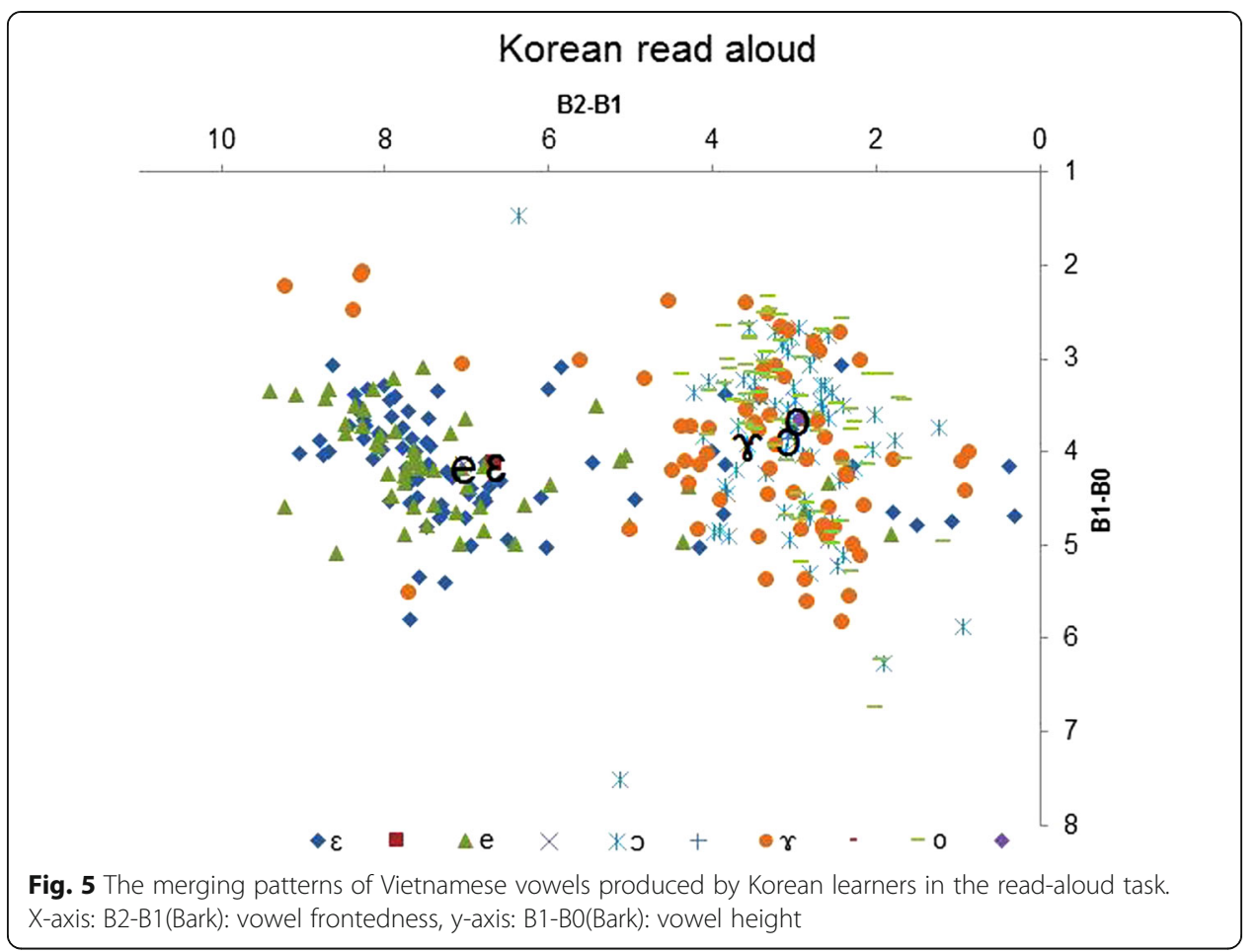

Korean read aloud and Vietnamese). The random effect was speakers (32 speakers: 11 control Vietnamese, 11 Korean learners, and 10 control Korean speakers). The use of REML overcomes the potentially serious deficiency of the ANOVA-based methods which assumed that data are sampled from a random population and normally distributed. REML also avoids bias arising from maximum likelihood estimators in which all fixed effects are known without errors, consequently tend to downwardly bias estimates of variance components. Moreover, REML can handle unbalanced data. The data analysis was carried out using the SPSS program. The results are reported in Table 3.

Second, in order to answer the second and third research questions, comparisons of vowel pairs, which have potential to overlap or merge, within each speaker groups (control Vietnamese, control Korean, Korean Imitation and Korean read aloud) were carried out within each of the three vowel sets $(/ \varepsilon /-/ \mathrm{e} /, / \mathrm{o} /-/ \mathrm{o} /-/ \gamma /$, and $/ \mathrm{u} /-/ \mathrm{w} /)$. The fixed effect was vowels. The random effect was speakers. A Tukey post-hoc test was then conducted to determine the significant differences among the levels of the main effects. The results are presented in Table 5 in Appendix.

\section{Results}

\section{Vietnamese and Korean cross-language comparisons of vowels}

The mixed effect modals showed significant effects for the main factor groups for all vowel pairs $(\mathrm{F}(3,332)=3.0-60.4, p<0.05-0.0001)$. As shown in Fig. 1 and Table 3 , Vietnamese and Korean vowels differ significantly in terms of vowel height (B1-B0, $p<0.02-0.001$ ) for vowels /a/, / $\varepsilon /, / \mathrm{e} /, / \mathrm{o} / \mathrm{/} / \mathrm{o} / \mathrm{and} / \mathrm{u} / \mathrm{l}$ By contrast, 


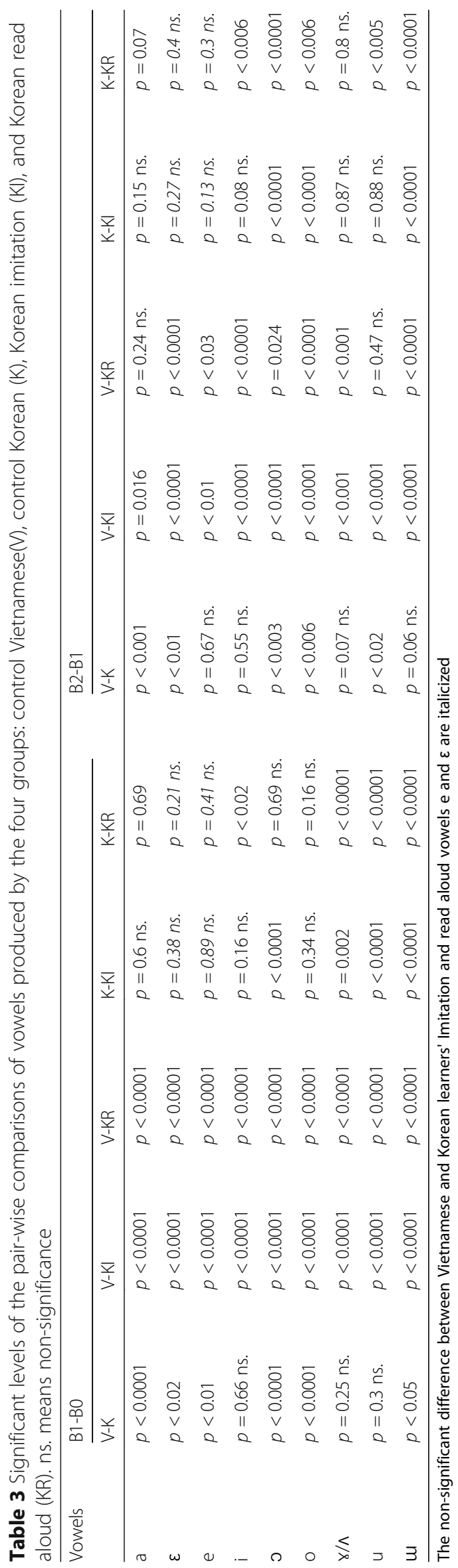


there are some overlapping of vowel height between the two languages, specifically between vowels such as Vietnamese /i/ and Korean/i/: $p=0.66$ ns., Vietnamese $/ \mathrm{r} /$ and Korean $/ \Lambda /: p=0.25$ ns., Vietnamese $/ \mathrm{u} /$ and Korean $/ \mathrm{u} /: p=0.3$ ns. In addition, there are also some overlapping of vowel frontedness between the two languages, particularly Vietnamese /e/-Korean /e/: $p=0.67$ ns., Vietnamese /i/ and Korean/i/: $p=0.55$ ns., Vietnamese / $/ /$ vs. Korean $/ \Lambda /: p=0.07$ ns., and Vietnamese /w/ vs. Korean / / $/ \mathrm{i} /: p=0.06$ ns. Particularly, it is shown by Fig. 1 that Korean vowels $/ \varepsilon /$ and $/ \mathrm{e} /$ merged across all speakers. In addition, Korean $/ \Lambda /$ is shown to be in proximity with Vietnamese $/ 0 /$ and $/ \gamma /$. Therefore, it is predicted that Korean L2 speakers of Vietnamese will have difficulty distinguishing the Vietnamese vowels $/ \varepsilon /$ and $/ \mathrm{e} /$. Furthermore, it is expected that they will have problems discriminating Vietnamese vowels $/ 0 /, / 0 /$ and $/ \gamma /$ in their production. By contrast, it is also predicted that they can produce acoustic differences for those L1-L2 vowels pairs that were highly dissimilar, such as $/ \mathrm{a} /(p<0.001)$.

\section{Vowel error patterns in read-aloud and imitation tasks}

As shown in Table 4, Korean learners produced significantly more Vietnamese-like vowels in the imitation task than in the read aloud task. This is indicated in the result of an ANOVA analysis with a significant effect for tasks $(p<0.0001)$. This is also

Table 4 Vowel error matrix in Read-Aloud and Imitation tasks. Vertical: Target Vietnamese vowels. Horizontal: Vietnamese vowels pronounced by Korean learners. The bolded figures indicate percentage of correct/native like vowel production. The italic figures indicate the major error patterns

\begin{tabular}{|c|c|c|c|c|c|c|c|c|c|c|}
\hline Vowels & $a$ & $\varepsilon$ & e & $\mathrm{i}$ & 0 & o & $\gamma$ & u & $m$ & $x$ \\
\hline \multicolumn{11}{|c|}{ Imitation } \\
\hline$a$ & 100 & 0 & 0 & 0 & 0 & 0 & 0 & 0 & 0 & 0 \\
\hline$\varepsilon$ & 0 & 62 & 17 & 0 & 0 & 0 & 0 & 0 & 0 & 21 \\
\hline e & 0 & 0 & 100 & 0 & 0 & 0 & 0 & 0 & 0 & 0 \\
\hline i & 0 & 0 & 0 & 73 & 0 & 0 & 0 & 0 & 0 & 27 \\
\hline o & 0 & 0 & 0 & 0 & 67 & 33 & 0 & 0 & 0 & 0 \\
\hline o & 0 & 0 & 0 & 0 & 8 & 88 & 0 & 0 & 0 & 5 \\
\hline$\gamma$ & 0 & 0 & 0 & 0 & 0 & 0 & 100 & 0 & 0 & 0 \\
\hline u & 0 & 0 & 0 & 0 & 0 & 0 & 0 & 100 & 0 & 0 \\
\hline$m$ & 0 & 0 & 0 & 0 & 0 & 0 & 0 & 0 & 98 & 2 \\
\hline \multicolumn{11}{|c|}{ Read aloud } \\
\hline a & 100 & 0 & 0 & 0 & 0 & 0 & 0 & 0 & 0 & 0 \\
\hline$\varepsilon$ & 0 & 23 & 9 & 0 & 0 & 0 & 0 & 0 & 0 & 68 \\
\hline e & 0 & 0 & 100 & 0 & 0 & 0 & 0 & 0 & 0 & 0 \\
\hline $\mathrm{i}$ & 0 & 0 & 0 & 100 & 0 & 0 & 0 & 0 & 0 & 0 \\
\hline o & 0 & 0 & 0 & 0 & 27 & 24 & 0 & 0 & 0 & 48 \\
\hline o & 0 & 0 & 0 & 0 & 6 & 89 & 0 & 0 & 0 & 5 \\
\hline$\gamma$ & 0 & 0 & 0 & 0 & 12 & 0 & 30 & 0 & 0 & 58 \\
\hline u & 0 & 0 & 0 & 0 & 0 & 0 & 0 & 65 & 11 & 24 \\
\hline$m$ & 0 & 0 & 0 & 0 & 0 & 0 & 0 & 2 & 94 & 5 \\
\hline
\end{tabular}


shown in the percentage of symbol $\mathrm{x}$ used: only $6.06 \%$ (36/594 items) of the items in the imitation task were identified by the two researchers as not sounding similar to any Vietnamese vowels. By contrast, in the read aloud task, 23.74\% (141/594 items) were identified as $\mathrm{x}$. This result suggests that Korean leaners accommodate to the native Vietnamese speaker to a greater extent in an imitation than in the read aloud task.

In the imitation task, there are two main error patterns: Korean learners have problems distinguishing Vietnamese vowel pairs $/ \varepsilon /-/ \mathrm{e} /$ and $/ \mathrm{o} /-/ \mathrm{o} / \mathrm{in}$ their production. Korean learners tend to produce Vietnamese vowel $/ \varepsilon /$ as /e/ (17\%) while they have no problem imitating Vietnamese vowel /e/. Similarly, they tend to produce vowel $/ \mathrm{o} / \mathrm{as} / \mathrm{o} /(33 \%)$. In the read aloud task, they also have difficulty producing the vowel $/ \varepsilon /$ (i.e., $/ \varepsilon /$ pronounced as $/$ e/: $9 \%$ and non-native like: 68\%). They also could not distinguish between /o/ and $/ \mathrm{o} / \mathrm{h} / \mathrm{o} / \mathrm{and} / \mathrm{\gamma} /$, and $/ \mathrm{u} /$ and $/ \mathrm{u} /$. These error patterns support the predictions in "Vietnamese and Korean cross-language comparisons of vowels" section.

\section{Acoustic comparison of Vietnamese vowels produced by Korean learners and control Vietnamese}

As shown in Figs. 2 and 3, Korean learners produced vowels which have significantly higher vowel height than those of control Vietnamese speakers across both tasks: imitation and read aloud. This mirror the pattern found in "Vietnamese and Korean cross-language comparisons of vowels" section: vowels of control Korean speakers also have higher vowel height than that of control Vietnamese.

In addition, Vietnamese vowels $/ \varepsilon /$ and $/ \mathrm{e} /$ produced by Korean learners merged in vowel space, supported by the statistical analysis as reported in Table 5 in Appendix and Figs. 4 and 5. This is consistent with the acoustic results in "Vietnamese and Korean cross-language comparisons of vowels" section and perception results by two phoneticians in "Vowel error patterns in read-aloud and imitation tasks" section. The statistical result in Table 3 also shows that there was no significant difference between Korean learners (KI and KR) and control Korean speakers (K) in terms of vowel /e/ and / $/$ / (the bolded results in Table 3), suggesting that the Korean learners assimilate their L2 Vietnamese vowels to their L1 Korean vowel.

Moreover, the three Vietnamese vowels $/ 0 /, / 0 /$ and $/ \gamma /$ produced by Korean learners in both tasks tend to cluster together. This is also supported by the statistical analysis in Table 5 in Appendix and Figs. 4 and 5. Specifically, there was no significant difference in vowel height of vowels $/ 0 /-/ \gamma /$ and the vowel frontedness of the vowels $/ 0 /-/ 0 /$ overlapped for both tasks (imitation and read aloud).

The statistical result (Table 5 in Appendix) indicates that Korean vowel pair $/ \mathrm{u} /-/ \mathbf{i} /$ has equivalent height (B1-B0: $p=0.44 \mathrm{~ns}$.). In contrast, Korean learners' (KI and KR) Vietnamese vowels $/ \mathrm{u} /-/ \mathrm{u} /$ are of the same vowel height (B1-B0: $p=0.78 \mathrm{~ns}$. and $p=$ 0.63 ns., respectively). 


\section{Discussion}

In this section, we summarize and discuss the results by addressing the three research questions raised in "Study aims and plans" section.

First, to what extent do Vietnamese and Korean vowels, as spoken by adult Vietnamese and Korean, differ or overlap in the acoustic phonetic space?

The result on cross language comparison showed that Vietnamese and Korean vowels differ significantly in terms of vowel height. By contrast, there are some overlapping of vowel frontedness between the two languages (particularly Vietnamese /e/-Korean /e/, Vietnamese /i/ and Korean/i/, Vietnamese / $/ \gamma /$ vs. Korean $/ \Lambda /$, and Vietnamese / $\mathrm{w} / \mathrm{vs}$. Korean $/ / \mathrm{i} /$ ). In addition, Korean vowels $/ \varepsilon /$ and /e/ were found to merge across all speakers. This is consistent with previous studies (Shin et al. 2013; Chung et al. 1988 and Umeda 1995). Furthermore, Korean $/ \Lambda /$ is shown to be in proximity with Vietnamese $/ \mathrm{o} /$ and $/ \gamma /$. By contrast, there were acoustic differences for those L1-L2 vowel pairs that were highly dissimilar, such as Vietnamese /a/ and Korean /a/.

Second, are the phonetic features of L1 Korean vowels transferred to L2 Vietnamese and how Korean learners accommodate to the target Vietnamese vowel systems?

The merging of $/ \varepsilon /$ and /e/ in Korean is transferred into Vietnamese, leading Korean learners to inability to distinguish the target language vowel contrast / $\varepsilon /$ and /e/ in production. This shows that an on-going phonemic merger in L1 can differentially impact upon learners' imitation and production of a similar vowel contrast in L2, consistent with findings on Korean learners' acquisition of English vowels in a previous study (Ingram and Park 1997). This could be predicted from any of the models of cross-language vowel perception (e.g., Flege 1995; Best 1995). It seems most likely that the L2 perception and production differences were expressions of L1 perceptual learning effects. In other words, incorrect perception of L2 phones by adult learners is considered to be due to the assimilation of L2 phones to L1 categories. This can be explained according to Best (1995) model: the Korean learners may have assimilated Vietnamese vowel $/ \varepsilon /$ and /e/ contrast to a single Korean /e/ category since there is no such counterpart of vowel $/ \varepsilon /$ in Korean vowel system due to the merger, and which shows the case of Single Category type. The same principle applies to the Vietnamese $/ 0 /$ and $/ 0 /$ contrast, Korean has $/ 0 /$ but not $/ 0 /$, thus they tend to pronounce Vietnamese $/ \mathrm{o} /$ as $/ \mathrm{o} /$, suggesting that they assimilated Vietnamese $/ \mathrm{o} / \mathrm{and} / \mathrm{o} /$ to a single Korean $/ 0 /$.

Furthermore, the three Vietnamese vowels $/ \mathrm{o} /, / \mathrm{o} / \mathrm{and} / \mathrm{\gamma} /$ produced by Korean learners in both tasks tend to cluster together. This may be due to the promixity in acoustic space of the Korean vowels $/ 0 /$ and $/ \Lambda /$ to the Vietnamese vowels $/ 0 /$, $/ \mathrm{o} / \mathrm{and} / \mathrm{r} /$. This provided insights into how cross-language similarity influenced the L1-L2 interaction. That is, when Vietnamese and Korean vowels were relatively similar acoustically, the Korean learners' renditions of L2 (Vietnamese) vowels were strongly "colored" by the acoustic properties of their L1 (Korean) vowels, consistent with findings by Trofimovich and Baker (2006) on Korean speakers of English.

In addition, the result on L2 vowel production also indicates that Korean learners' Vietnamese vowels are higher than those of the control Vietnamese, suggesting that 
Korean leaners tend to transfer their L1 vowel acoustic space into the production of Vietnamese vowels.

Third, how would the amount of similarity between Korean L1 and Vietnamese L2 sounds determine the degree of L1-L2 interaction in late bilinguals?

The results of this study indicated that cross-language similarity indeed influenced how the L2 vowels are produced. That is, vowels that were highly similar across the two languages were more likely to influence each other (such as / $/$ / and /e/) than those vowels that were dissimilar (such as /a/). The late bilinguals in this study produced acoustic differences only for those L1-L2 vowel pairs that were highly dissimilar, such as Vietnamese /a/ and Korean/a/. Assuming that L1-L2 interaction implies restructuring of the L1 and L2 phonetic system(s), then the degree of acoustic similarity between L1 and L2 sounds constrains what sounds undergo such a restructuring and the degree to which it does so (Trofimovich et al. 2001). The interaction hypothesis (Flege et al. 1995) may explain why cross-language similarity is more likely to determine how adult L2 learners organize their phonetic system(s). Because late bilinguals' L1 categories are fully developed, they are more likely to produce even perceptually dissimilar L1 and L2 sounds with L1-based acoustic properties (Aoyama et al. 2004) and to perceive such L2 sounds in terms of an L1-based category (Guion et al. 2000; Trofimovich et al. 2001). The late bilinguals in this study may require an amount of experience with the L2 that is far greater than that explored in this study (more than 1 year) in order to overcome the pervasive effect of their L1 on their processing and learning of L2 sounds (Flege et al. 1995; Trofimovich et al. 2001).

Additionally, the result of the study also implies the effect of Korean learners' vowel perception on their production by means of the imitation task. The fact that they failed to imitate the vowel pairs $/ \varepsilon /-/ \mathrm{e} /$ and $/ \mathrm{o} /-/ \mathrm{o} /$ accurately suggests that they have problems perceiving the vowel contrast in L2. Flege (1995) pointed to the importance of the relationship between perception and production. He hypothesized that accurate perception of L2 sounds will eventually lead to the successful production of L2 phones. If an L2 learner shows difficulty in discriminating L2 contrasts, the learner would also have the same difficulty producing correct L2 phones in L2 learning. Further research examining how cross-language similarity influences the perception of the L2 may indicate to what extent this ability constrains both the perception and the production abilities of bilinguals.

Furthermore, Korean learners produced significantly more Vietnamese-like vowels in the imitation task than in the read aloud task. This result suggests that Korean leaners accommodate to the native Vietnamese speaker to a greater extent in an imitation than in the read aloud task. This can be explained by the phonetic convergence effect which is defined as the process by which a talker takes on acoustic characteristics of the individual that he or she is interacting with (Babel 2012). The results revealed a significant convergence with the model in the task in which speakers were required to immediately repeat after the model voice (imitation task) compared to the task in which they read orthographic representations of the words (read aloud task). Hence, it suggests that foreign language learners are able to modify their productions of non-native 
vowels as a result of exposure to the model. The result that Korean learners become more similar in their production to the target language speaker in the imitation task would also imply that fine-grained phonetic details are not filtered out in speech perception and detailed auditory traces associated with perceived words are stored in memory and are then used for production (Dufour and Nguyen 2013).

Finally, the result of this study is consistent with that of Baker and Trofimovich (2005) who found that late bilinguals tended to rely mostly on their L1 sound category in the process of L2 production, however, in their study, early bilinguals seem to establish a new sound category for L2 contrasts distinct from their L1, which helps the early bilinguals perform more proficient L2 production. Although the late bilinguals in this study and in Baker and Trofimovich (2005)'s research have a certain amount of L2 experience, their L2 experience plays very little of a role in L2 acquisition. This showed that L2 learners' age plays a substantial role in the relationship between L2 experience and a successful L2 acquisition. In other words, earlier age of L2 acquisition shows a better effect on L2 acquisition than a later age of L2 learning. Therefore, the findings of this study are limited to adult's situation. Nevertheless, Jung (2016)'s study provided some evidence for the claim of developmental stages of L2 learning. In the Second-Language Linguistic Perception (L2LP) model, Escudero (2006) proposed a developmental process of L2 learning. The model suggested that a full copy of L1 sound occurs at the initial state of L2 learning, and through creating and adjusting L1 and L2 category, at the end state, advanced L2 learners begin to separate the L1 and L2 sound system. Escudero asserted that the existence of a separate sound category of L1 and L2 leads the learners to an optimal stage of L2 perception. The L2LP model also proposed that the key to L2 development is driven by rich L2 input such as qualified L2 instruction. L2 learners are able to benefit from L2 community environments as well by acquiring critical auditory cues from a target community. Therefore, future studies should include additional Korean participants with intermediate or higher levels and with "richer L2 input and/or qualified L2 instruction" that could reveal a variety of transfer effect and L2 development process.

\section{Conclusion}

In summary, this paper presents new data and results on the roles of language-specific phonological learning and inherent phonetic contrastiveness in the production of non-native vowels. The results of this study provide evidence that Korean learners transfer their L1 vowel quality features into the production of Vietnamese vowels. The findings of this study have an original and significant contribution to the literature because first, it presents a novel comparison: the acquisition of Vietnamese as an L2 is still understudied. Second, it contributes to the understanding of the process and nature of second language acquisition. While the results of this study are specific to Korean and Vietnamese, their implications can be extended to the acquisition of other languages. In fact, a series of studies on speakers of other languages (e.g. Lao, Taiwanese and Japanese) learning Vietnamese as an L2 are being conducted by the authors. 


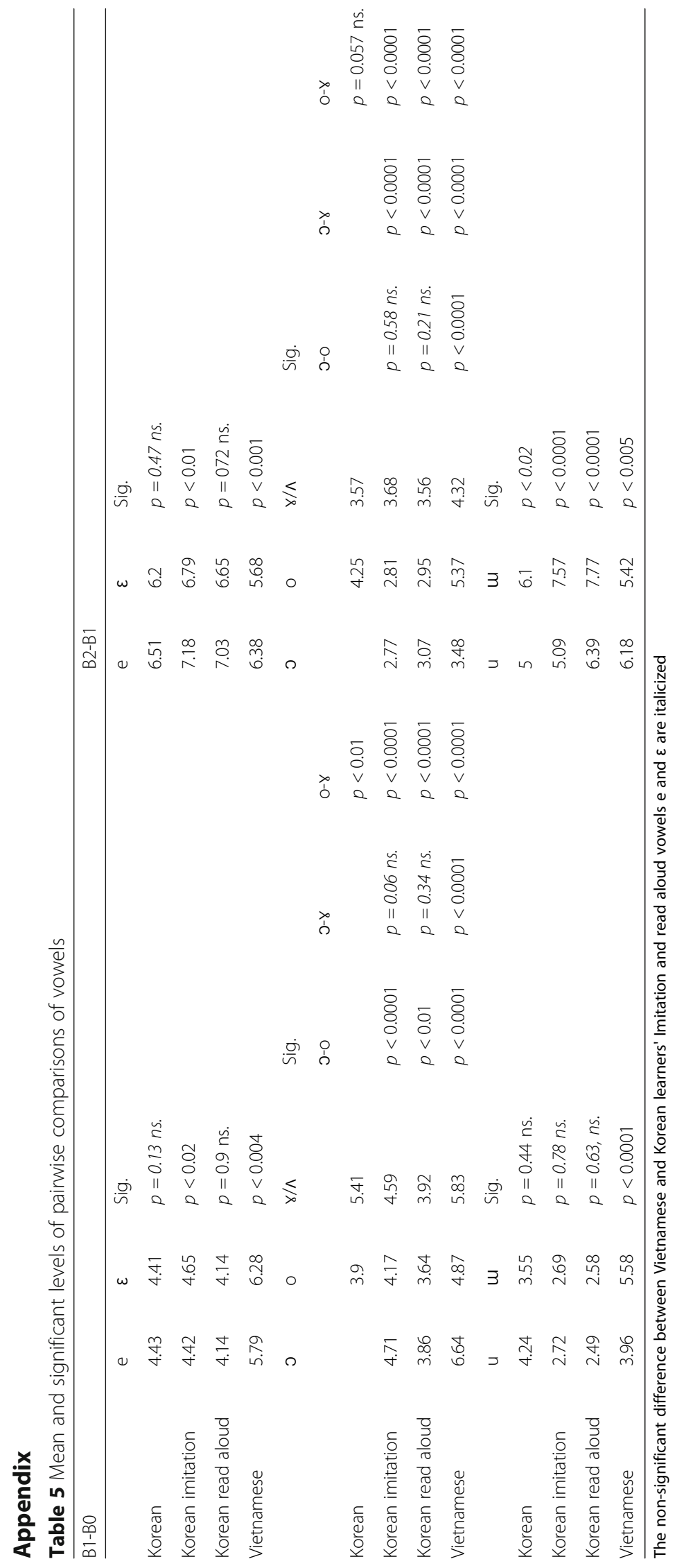




\section{Abbreviations}

B: Bark; B1-B0: Vowel height values; B2-B1: Vowel frontedness values; F0: Fundamental frequency; F1: First vowel formant; F2: Second vowel formant; K: Control Korean; KI: Korean imitation; KR: Korean read aloud; L1: Native language; L2: Second language; L2LP: Second-Language Linguistic Perception model; PAM: Perceptual Assimilation Model; REML: Restricted maximum likelihood; SC: Single Category; SD: Standard deviation; SLM: Speech Learning Model; TC: Two Category; V: Control Vietnamese

\section{Acknowledgements}

We would like to thank the subjects for their voluntary participation in the experiment. We also thank the two anonymous reviewers for their constructive comments.

\section{Authors' contributions}

M-DD collected the data. A-TTN conducted the acoustic and statistical analysis of the data and wrote the paper. Both authors designed the experiments, read and approved the final manuscript.

\section{Competing interests}

The authors declare that they have no competing interests.

\section{Publisher's Note}

Springer Nature remains neutral with regard to jurisdictional claims in published maps and institutional affiliations.

\section{Author details}

${ }^{1}$ University of Social Sciences and Humanities, National Vietnamese University of Ho Chi Minh City, Ho Chi Minh City, Vietnam. ${ }^{2}$ Mountain Creek QLD 4557, Australia.

Received: 22 March 2018 Accepted: 31 July 2018

Published online: 16 August 2018

\section{References}

Aoyama, K., Flege, J. E., Guion, S. G., Akahane-Yamada, R., \& Yamada, T. (2004). Perceived phonetic dissimilarity and L2 speech learning: The case of Japanese /r/ and English /r/ and / I/. Journal of Phonetics, 23, 233-250.

Babel, M. (2012). Evidence for phonetic and social selectivity in spontaneous phonetic imitation. Journal of Phonetics, 40, $177-189$

Baker, W., \& Trofimovich, P. (2005). Interaction of native- and second-language vowel system(s) in early and late bilinguals. Language \& Speech, 48, 1-27.

Best, C. T. (1995). A direct realist view of cross-language speech perception. In W. Strange (Ed.), Speech perception and linguistic experience: issues in cross - language research (pp. 171-203). Baltimore: York Press.

Boersma, P. \& Weenink, D. (2017). Praat: doing phonetics by computer (version 6.0.26). computer program. Retrieved 1 Jan 2017, from http://www.praat.org/ California, Los Angeles.

Bohn, O.-S., \& Flege, J. (1990). Interlingual identification and the role of foreign language experience in L2 vowel perception. Applied PsychoLinguistics, 11, 303-328.

Brunelle, M. (2015).Vietnamese (Tiếng Việt). The handbook of Austroasiatic languages (pp. 909-954). Leiden: Brill.

Chung, H, Makino, S, \& Kido, K (1988). Analysis and recognition of Korean isolated vowels using formant frequency. Journal of the Acoustic Society of Japan, 9(5), 225-232.

Crothers, J. (1978). Typology and universals of vowel systems. Universals of human language. In J. H. Greenberg (Ed.), Phonology (Vol. 2, pp. 95-152). Stanford: Stanford University Press.

Dinh, L. T., \& Nguyen, V. H. (1998). Cơ C u ngữ âm tiếng Việt [Structure of Vietnamese phonetics]. Thành ph Hồ Chí Minh: Giáo Duc Press.

Đoàn, T. T. (1977). Ngữ âm tiếng Việt Vietnamese phonetics] (pp. 1-371). Nhà Xu t B n Đại H c Qu c Gia: Hà N i.

Dufour, S., \& Nguyen, N. (2013). How much imitation is there in a shadowing task? Frontiers in Psychology, 4, 1-7.

Emerich, G. H. (2012). The Vietnamese vowel system. Ph.D thesis. University of Pensylvania.

Escudero, P. (2006). The phonological and phonetic development of new vowel contrasts in Spanish learners of English. In B. Baptista \& M. Watkins (Eds.), English with a Latin beat: studies in Portugues/Spanish-English interphonology. Studies in bilingualism (Vol. 31, pp. 149-161). Amsterdam: John Benjamins.

Flege, J. (1999). The relation between L2 production and perception. In J. Ohala, Y. Hasegawa, M. Ohala, D. Granveille, \& A. Bailey (Eds.), Proceedings of the XIVth International Congress of Phonetics Sciences (pp. 1273-1276). Berkeley: Department of Linguistics, Univ. of California at Berkeley.

Flege, J., \& Hillenbrand, J. (1984). Limits on pronunciation accuracy in adult foreign language speech production. Journal of the Acoustical Society of America, 76, 708-721.

Flege, J. E. (1987). The production of "new" and "similar" phones in a foreign language: Evidence for the effect of equivalence classification. Journal of Phonetics, 15, 47-65.

Flege, J. E. (1992). Talker and listener effects on degree of perceived foreign accent. Journal of the Acoustical Society of America, 91(1), 370-389.

Flege, J. E. (1995). Second language speech learning theory, findings, and problems. In W. Strange (Ed.), Speech perception and linguistic experience: issues in cross - language research (pp. 233-277). Baltimore: York Press.

Flege, J. E., \& Munro, M. J. (1994). Auditory and categorical effects on cross-language vowel perception. Journal of the Acoustical Society of America, 95(6), 3623-3641.

Flege, J. E., Munro, M. J., \& MacKay, I. R. A. (1995). Factors affecting degree of perceived foreign accent in a second language. Journal of the Acoustical Society of America, 97, 3125-3134. 
Guion, S., Flege, J., Akahane-Yamada, R., \& Pruitt, J. (2000). An investigation of current models of second language speech perception: The case of Japanese adults' perception of English consonants. Journal of the Acoustical Society of America, 107, 2711-2725.

Han, M. S. (1966). Vietnamese vowels. Studies in the phonology of Asian languages 4. Los Angeles: Acoustic Phonetics Research Laboratory, University of Southern California.

Han, M. S. (1968). Complex syllable nuclei in Vietnamese. Studies in the phonology of Asian languages (vol. 6); U.S. Office of Naval Research. Los Angeles: University of Southern California.

Haudricourt, A. G. (1952). Les Voyelles brèves du vietnamien. Bulletin de la Société de Linquistique de Paris, 48(1), 90-93.

Huh, W. (1952). Ay, ey, oy, o uy umka ("on the sound quality of ay, ey, oy, o, o"). Kukeo Kukmunhak, 1, 5-8 (in Korean).

Huh, W. (1991). Korean phonology. Seoul: Sam Munhwasa (in Korean).

Hwang, H., \& Moon, S. (2005). An acoustic comparative study of Korean /에, OH/ and English /E, æ/ pronounced by Korean young male speakers. Malsori, 56, 29-47 (in Korean).

Ingram, J. C., \& Park, S.-G. (1997). Cross-language vowel perception and production by Japanese and Korean learners of English. Journal of Phonetics, 25(3), 343-370.

Jun, S.-A., \& Cowie, I. (1994). Interference for 'new' versus 'similar' vowels in Korean speakers of English. In Working papers in linguistics (Vol. 43, pp. 117-130). Dept. of Linguistics, The Ohio State University.

Jung, J. E. (2016). A developmental process of English vowel acquisition by Korean adult L2 learners. Ph.D dissertation. Buffalo: State University of New York.

Kirby, J. P. (2011). Vietnamese (Hanoi Vietnamese). Journal of the International Phonetic Association, 41(3), 381-392.

Le, V. L. (1960). Le Parler Vietnamien (2nd ed.). Saigon: Bo Quoc Gia Giao Duc.

Lee, H. (1996). Korean phonetics. Seoul: Taehaksa (in Korean).

Nguyễn, B. T. (1949). Chữ và Vần Việt Nam Khoa H C [scientific study of Vietnamese letters and syllables]. Sài Gòn: Ngôn Ngữ.

Nguyễn, B. T. (1959). Ngôn Ngữh c Việt Nam [Vietnamese linguistics]. Sài Gòn: Ngôn Ngữ.

Nguyễn, Đ. H. (1997). Tiếng Việt Không Son Ph n [Vietnamese without veneer]. Amsterdam: John Benjamins.

Shin, J. (2000). Understanding spoken language. Seoul: Hankuk Munhwasa (in Korean).

Shin, J., Kiaer, J., \& Cha, J. (2013). The sounds of Korean. Cambridge: Cambridge University Press.

Smalley, W. A., \& Nguyen, V. V. (1957). Vietnamese for missionaries: a course in the spoken and written language of Central Viet Nam, I \& II. Saigon.

Sohn, H. (1999). The Korean language. Cambridge: Cambridge University Press (in Korean).

Syrdal, A. K., \& Gopal, H. S. (1986). A perceptual model of vowel recognition based on the auditory representation of American English vowels. The Journal of the Acoustical Society of America, 79, 1086-1100.

Thompson, L. C. (1965). A Vietnamese reference grammar. Honolulu: University of Hawai'i Press.

Trofimovich, P., Baker, W., \& Mack, M. (2001). Context and experience-based effects on the learning of vowels in a second language. Studies in the Linguistic Sciences, 31(2), 167-186.

Trofimovich, P., \& Baker, W. (2006). Learning second language suprasegmentals: Effect of L2 experience on prosody and fluency characteristics of L2 speech. Studies in Second Language Acquisition, 28, 1-30.

Umeda, H. (1995). Age differentiation of the vowel system in the Seoul Korean: Acoustic measurements. Journal of Asian and African Studies, 48-49, 443-453.

Wiersma, W. (2000). Research methods in education: an introduction. Boston: Allyn and Bacon.

Winn, M., Blodgett, A., Bauman, J., Bowles, A.r Charters, L., Rytting, A., \& Shamoo, J. (2008). Vietnamese monophthong vowel production by native speakers and American adult learners. In Proceedings of acoustics '08 (pp. 6125-6130).

Yang, B. (1996). A comparative study of American English and Korean vowels produced by male and female speakers. Journal of Phonetics, 24, 245-261.

Yoon, T.-J., Kang, Y., Han, S., Maeng, H., Lee, J., \& Kim, K. (2015). A corpus-based approach to dialectal variation in Korean vowels. In Proceedings of the 18th ICPhS.

\section{Submit your manuscript to a SpringerOpen ${ }^{\circ}$ journal and benefit from:}

- Convenient online submission

- Rigorous peer review

- Open access: articles freely available online

High visibility within the field

- Retaining the copyright to your article

Submit your next manuscript at $\boldsymbol{\nabla}$ springeropen.com 